\title{
Experimental investigation of equivalence ratio fluctuations in a lean premixed kerosene combustor
}

\author{
Manuel Vogel $^{1}$ (D) Michael Bachfischer $^{1}$ (D) Jan Kaufmann ${ }^{1}$ (D) Thomas Sattelmayer $^{1}$ (D)
}

Received: 18 November 2020 / Revised: 18 March 2021 / Accepted: 27 March 2021 / Published online: 12 April 2021

(c) The Author(s) 2021

\begin{abstract}
In this study a measurement technique for determination of equivalence ratio fluctuations from flame chemiluminescence in a kerosene-fuelled lean premixed combustor under atmospheric conditions is presented. Firstly, fundamental investigations into the relationship between the ratio of different chemiluminescence signals and the equivalence ratio are carried out using an imaging spectrometer. The chemiluminescence intensity is recorded for a wide range of equivalence ratios and fuel mass flows during steady state operation. The spectra show that the $\mathrm{CH}^{*} / \mathrm{OH}^{*}$ ratio depends linearly on the equivalence ratio and is independent of the mass flow in the investigated range. Moreover, the background radiation has no influence on the monotonous trend of the $\mathrm{CH}^{*} / \mathrm{OH}^{*}$ ratio for kerosene combustion. This interesting finding opens up new possibilities for passive optical measurement of the equivalence ratio in kerosene flames. Bandpass-filtered phase-correlated images of $\mathrm{OH}^{*}$ and $\mathrm{CH}^{*}$ chemiluminescence of an acoustically excited flame are taken simultaneously on one camera chip using an image doubler. After distortion correction, the image pair is used to calculate the global equivalence ratio from the $\mathrm{CH}^{*} /$ $\mathrm{OH}^{*}$ ratio. Based on the calibration chart derived in stationary operation, phase-resolved equivalence ratio perturbations are determined during acoustic excitation. The presented technique allows a quantitative measurement of equivalence ratio fluctuations in spray combustion and can therefore provide a better understanding of the fundamental mechanisms of thermoacoustic instabilities triggered by equivalence ratio fluctuations.
\end{abstract}

Manuel Vogel

vogel@td.mw.tum.de

1 Chair of Thermodynamics, Technical University of Munich, Boltzmannstr. 15, 85748 Garching, Germany 


\section{Graphic abstract}
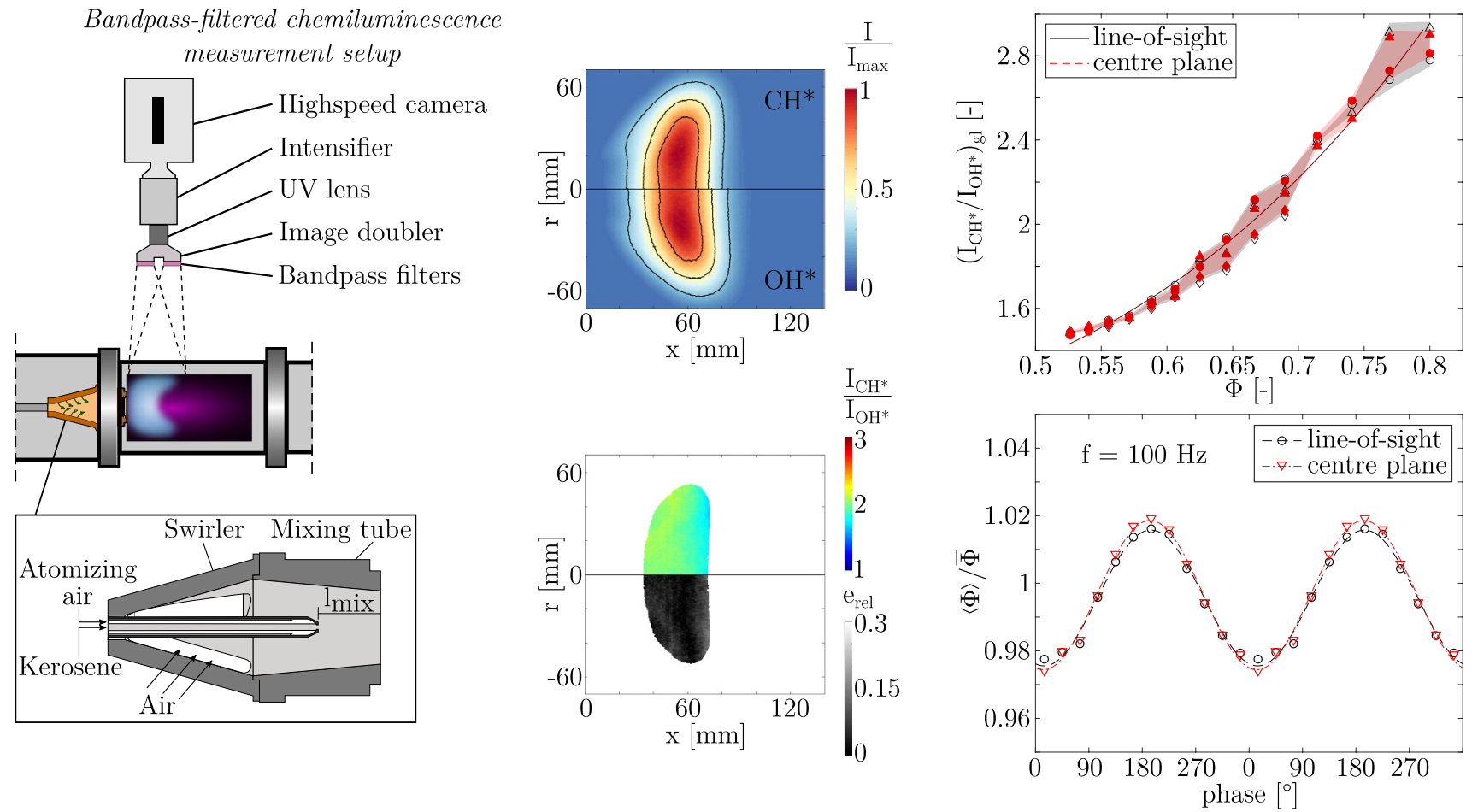

\section{List of symbols}

$e_{\text {rel }} \quad$ Local deviation from the average value (-)

$f \quad$ Frequency $(\mathrm{Hz})$

$T \quad$ Temperature (K)

$u \quad$ Axial velocity $(\mathrm{m} / \mathrm{s})$

$U \quad$ Axial bulk velocity $(\mathrm{m} / \mathrm{s})$

$x \quad$ Axial coordinate (m)

\section{Greek letters}

$\varphi \quad$ Phase (rad)

$\varphi_{k} \quad$ Phase shift (rad)

$\Phi \quad$ Global equivalence ratio (-)

\section{Subscripts}

$(\cdot)_{\mathrm{gl}} \quad$ Global mean value

$(\cdot)_{\max }$ Maximum

$(\cdot)_{\operatorname{mix}}$ Mixing

$(\cdot)_{\text {pre }} \quad$ Preheater

\section{Operators}

(.) Amplitude

$(\cdot)^{\prime} \quad$ Deterministic (coherent) component

$|\cdot| \quad$ Magnitude

$\langle\cdot\rangle \quad$ Phase-averaged mean value

$(\tilde{\cdot)} \quad$ Random (stochastic) component

$\overline{(\cdot)} \quad$ Time-averaged mean value
$I_{(\cdot)} \quad$ Chemiluminescence intensity $\left(\mathrm{W} / \mathrm{m}^{2}\right)$

$l \quad$ Length (m)

$r \quad$ Radial coordinate (m)

\section{Abbreviations}

$\mathrm{A}^{2} \mathrm{EV} \quad$ Advanced $^{2}$ En-Viromental burner

ICCD Intensified charge coupled device

UV Ultraviolet

\section{Introduction}

Modern gas turbine engines used in power generation are mainly operated at lean premixed combustion conditions to comply with current regulatory requirements (Candel et al. 2013). The change from diffusion combustion to premixed combustion has led to a significant reduction in nitrogen oxide emissions. At the same time, however, these low-pollution combustors are prone to the formation of thermoacoustic instabilities causing significant pressure and temperature amplitudes in the combustion chamber (Lieuwen and Yang 2005; Huang and Yang 2009). These are caused by a feedback loop between acoustic waves in the combustion chamber and fluctuations in the heat release rate. Investigations of lean premixed gas turbine combustion dynamics have revealed that the heat release fluctuations can be attributed to two coupling mechanisms (Ducruix et al. 2003; Lieuwen et al. 2001). Firstly, acoustically initiated velocity fluctuations at 
the burner outlet lead to a large-scale coherent vortex formation of a combustible mixture. If hot product gas penetrates the vortices, they burn abruptly and can act as a source of acoustic energy. In addition, the convectively transported vortices cause a fluctuation of the flame surface, which also leads to a modulation of the heat release (Huang and Yang 2009; Lieuwen 2013). Secondly, in technically premixed combustion systems, equivalence ratio fluctuations at the burner outlet can additionally lead to a fluctuation in the heat release. Equivalence ratio fluctuations are caused by acoustic pressure and velocity fluctuations at the location of the fuel supply. Convectively transported to the flame, they lead to fluctuations in the heat release. The flame temperature is also affected by equivalence ratio fluctuations leading to the formation of entropy waves, which influence the acoustics of the system (Sattelmayer 2003; Lieuwen and Zinn 1998).

While extensive studies on combustion instabilites have already been carried out using gaseous fuels (Keller 1995; Alemela et al. 2010; Bade et al. 2013), the effects of the combustion of liquid fuels on the flame dynamics have mainly been investigated for non-premixed, rich combustion (Konrad et al. 1998; Zhu et al. 2001; Eckstein et al. 2005). Due to the additionally necessary sub-processes of atomization and vaporization, a complex interaction of the acoustic velocity fluctuations with the mixture preparation in the mixing tube arises. This leads in particular to a different route for the formation of equivalence ratio fluctuations at the burner outlet. A description of influence of acoustic velocity fluctuations on the atomization and thus on the droplet size distribution for a non-premixed, rich combustion was published by Eckstein (2004). It has been observed that even small velocity fluctuations can have a significant effect on the droplet distribution and thus cause a significant modulation of the heat release fluctuations (Eckstein et al. 2005). The velocity fluctuations in the atomization area are a direct response of the pressure fluctuations in the combustion chamber. The unstable oscillation frequency is dominated by the transport and combustion time scales of the droplets.

In contrast to this, lean premixed spray combustion dynamics have scarcely featured in research up until now. Since equivalence ratio fluctuations are one of the major mechanisms causing thermoacoustic instabilities in lean premixed combustion, the development of a reliable measurement technique for determining equivalence ratio fluctuations is a key challenge. It has been shown that monitoring the flame chemiluminescence is a potential solution for determining the equivalence ratio in the reaction zone (Docquier et al. 2002; Hardalupas and Orain 2004; Muruganandam et al. 2005).

The first researcher to report a relationship between the ratios of different chemiluminescence signals and the equivalence ratio was Clark (1958). He observed a clear correlation between the $\mathrm{C}_{2} * / \mathrm{CH}^{*}$ ratio and the equivalence ratio for propane-air flames under atmospheric conditions. In later studies Kojima et al. (2000) showed that the $\mathrm{OH}^{*} /$ $\mathrm{CH}^{*}, \mathrm{C}_{2} * / \mathrm{CH}^{*}$ and $\mathrm{C}_{2} * / \mathrm{OH}^{*}$ ratios can be used to determine the local equivalence ratio in the reaction zone of premixed laminar methane-air flames. $\mathrm{C}_{2} * / \mathrm{OH}^{*}$ was found to be most sensitive to the equivalence ratio. In lean premixed flames the $\mathrm{C}_{2} *$ emission intensity is very low, so the $\mathrm{OH}^{*} / \mathrm{CH}^{*}$ ratio is more appropriate for determining the equivalence ratio. Similar observations have been reported for premixed natural gas-air and propane-air counterflow flames (Hardalupas and Orain 2004; Orain and Hardalupas 2010, 2011). It was shown that the $\mathrm{OH}^{*} / \mathrm{CH}^{*}$ ratio is a monotonic function of the equivalence ratio and is also independent of the strain rate. These findings are corroborated by numerical simulations of counterflow flames with detailed chemistry (Panoutsos et al. 2009). Eight detailed chemistry mechanisms, extended by elementary reactions that account for the formation and deactivation of the chemiluminescence species $\mathrm{OH}^{*}$ and $\mathrm{CH}^{*}$, were investigated. The numerical results were in good agreement with the experimental data. It was also found that the $\mathrm{OH}^{*} / \mathrm{CH}^{*}$ ratio is unaffected by the flame strain rates, although the chemiluminescence intensities of $\mathrm{OH}^{*}$ and $\mathrm{CH}^{*}$ are strongly dependent on the strain rate. While flame parameters such as turbulence intensity and strain rate show strong influence on the chemiluminescence intensity of $\mathrm{OH}^{*}$ and $\mathrm{CH}^{*}$, the ratio of $\mathrm{CH}^{*} / \mathrm{OH}^{*}$ is found to be almost independent of these parameters for turbulent flames at atmospheric conditions (Guyot et al. 2010; Bobusch et al. 2013). Muruganandam et al. (2005) examined the applicability of chemiluminescence sensing to technical applications by investigating the $\mathrm{OH}^{*} / \mathrm{CH}^{*}$ ratio in various natural gas combustor configurations at pressures up to 7.8 bar. They found that neither minor fuel changes, nor air preheating, nor velocity affect the relationship of the $\mathrm{OH}^{*} / \mathrm{CH}^{*}$ ratio and the equivalence ratio. Moreover, a non-monotonic behaviour of the $\mathrm{OH}^{*} / \mathrm{CH}^{*}$ ratio at varying equivalence ratios with increasing pressure was observed.

Until now, the relationship between the ratio of different chemiluminescence signals and the equivalence ratio for liquid fuelled flames has not been widely investigated. Yi and Santavicca (2009) studied the spectrum of a turbulent swirl-stabilized flame using Jet A1 as fuel. They reported the spectrum of the liquid fuelled combustor to be very similar to that of lean premixed gaseous combustion. Lee and Seo (2015) also analyzed the spectral characteristics of kerosene swirl combustion. They reported that the $\mathrm{OH}^{*} / \mathrm{CH}^{*}$ ratio assumes values close to one, independent of the equivalence ratio and preheating temperature, and thus shows no monotonic relationship to the equivalence ratio. The ratio $\mathrm{C}_{2} * /$ $\mathrm{CH}^{*}$ showed a linear correlation as a function of the equivalence ratio. They observed a decreasing gradient of the $\mathrm{C}_{2} * /$ $\mathrm{CH}^{*}$ ratio with increasing swirl number. Similar results were 
published by Józsa and Kun-Balog (2015) for the combustion of diesel oil. They also observed a non-monotonous characteristic of the $\mathrm{OH}^{*} / \mathrm{CH}^{*}$ ratio with the equivalence ratio. Moreover, they stated that the $\mathrm{OH}^{*} / \mathrm{CH}^{*}$ ratio was dependent on the atomizing air pressure. The $\mathrm{C}_{2} * / \mathrm{CH}^{*}$ and $\mathrm{C}_{2} * / \mathrm{OH}^{*}$ ratios indicated very low sensitivity to the atomizing pressure and exhibited a monotonous relationship with the equivalence ratio.

The chemiluminescence from $\mathrm{OH}^{*}, \mathrm{CH}^{*}$ and $\mathrm{C}_{2} *$ is superimposed by a broadband background radiation, which can be attributed to $\mathrm{CO}_{2} *$ and $\mathrm{HCO} *$ (Najm et al. 1998). All presented studies take this into account and thus all ratios are corrected for background radiation. In summary, it can be stated that the relationship between the ratio of different chemiluminescence species and the equivalence ratio taking background radiation into account has already been comprehensively investigated. The influence of background radiation on this relationship has only been studied for a couple of fuels so far. Hardalupas and Orain (2004) showed that the $\mathrm{OH}^{*} / \mathrm{CH}^{*}$ ratio without taking background radiation into account still exhibits a monotonic relationship to the equivalence ratio for natural gas flames. Reyes et al. (2018) investigated the relationship between the $\mathrm{C}_{2} * / \mathrm{CH}^{*}$ ratio without background correction and the equivalence ratio for gasoline in a constant volume combustion chamber at pressures up to 10 bar. They reported a monotonic relationship between the $\mathrm{C}_{2} * / \mathrm{CH}^{*}$ ratio and the equivalence ratio for all charge pressures investigated. Furthermore, they observed an increasing sensitivity of the $\mathrm{C}_{2} * / \mathrm{CH}^{*}$ ratio with increasing charge pressure. However, the influence of background radiation on this relationship for kerosene combustion has not yet been investigated. This study examines the influence of background radiation on the relationship between the ratio of different chemiluminescence signals and the equivalence ratio.

The current paper introduces a measurement technique for the determination and quantification of equivalence ratio fluctuations for spray combustion based on observation of the flame chemiluminescence.

Firstly, spectrally resolved chemiluminescence investigations are conducted providing a correlation between the chemiluminescence signal and the equivalence ratio. Secondly, these findings are transferred to the bandpass-filtered chemiluminescence technique developed in previous studies (Lauer 2011). As a result, the measurement technique for determining equivalence ratio fluctuations is significantly simplified. Phase-correlated images of the $\mathrm{OH}^{*}$ and $\mathrm{CH}^{*}$ chemiluminescence are acquired simultaneously on one camera chip to identify fluctuations in the equivalence ratio during an oscillation cycle. This measurement technique enables a more detailed investigation of thermoacoustic instabilities caused by equivalence ratio fluctuations.

\section{Experimental setup and measurement techniques}

\subsection{Single burner test rig}

The atmospheric single burner test rig used for all experimental investigations presented in this study is shown schematically in Fig. 1. The main airflow first passes through an electrical preheater to provide a constant combustor inlet temperature of $T_{\text {pre }}=573 \mathrm{~K}$. Before entering the plenum,

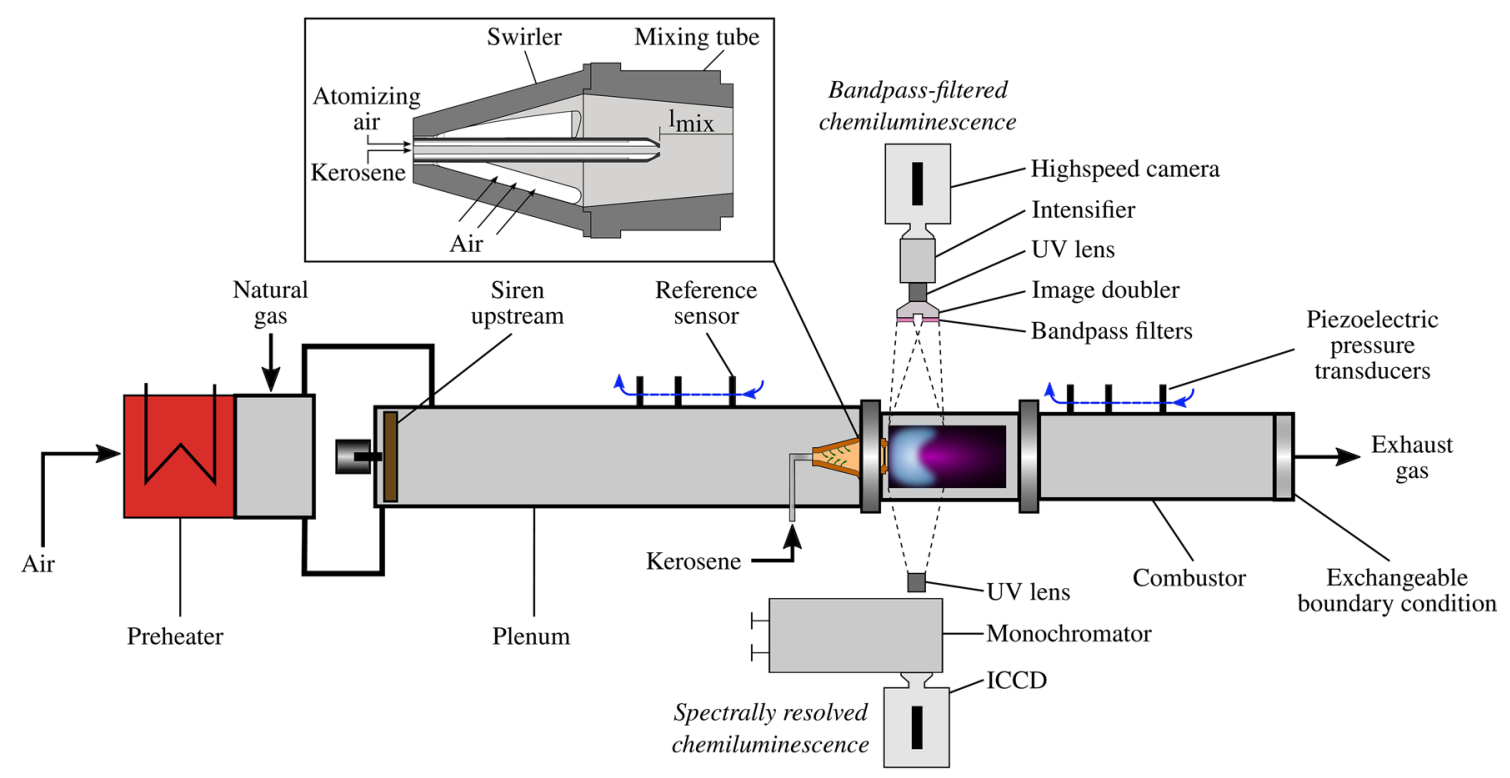

Fig. 1 Schematic sketch of the single burner test rig with modular swirl burner system and measurement techniques 
the flow is divided into two partial flows, one flows straight to the plenum through a bypass and the other one is supplied to the upstream siren for acoustic excitation. The plenum is a cylindrical tube with an inner diameter of $124 \mathrm{~mm}$ and a length of $1365 \mathrm{~mm}$. The siren generates a harmonic acoustic signal using a disc with double sine shaped orifices (Eckstein 2004). The siren shaft is connected to a $1.1 \mathrm{~kW}$ three-phase motor providing a nominal torque of $3.7 \mathrm{Nm}$. The achievable excitation amplitudes are influenced by the supplied air mass flow. Effectively, excitation frequencies of up to $f=800 \mathrm{~Hz}$ can be generated.

The combustion chamber has a square cross-section with a side length of $150 \mathrm{~mm}$ and a total length of $730 \mathrm{~mm}$. It is optically accessible through a quartz glass window for observation of the flame. A downscaled version of the $A^{2} E V$ burner is used in this study (Sangl et al. 2011; Bade et al. 2013). The burner consists of a diverging swirler with a length of $68 \mathrm{~mm}$ followed by a converging mixing tube of length $60 \mathrm{~mm}$. The outlet diameter of the mixing tube is $32 \mathrm{~mm}$. The swirler has a central hole and four tangential slots. The burner is extended by a central twin-fluid nozzle on the burner axis to enable the injection of liquid fuel. A schematic sketch of the burner with the twin-fluid nozzle is also shown in Fig. 1. The twin-fluid nozzle is fed with kerosene and air. A stream of high velocity atomizing air is brought into contact with a liquid flow. Therefore, this nozzle can generate fine droplets at low liquid velocities (Ashgriz 2011). This is an internal mixing nozzle where gas and liquid are brought into contact within the nozzle. The distance between the nozzle and the combustion chamber inlet is definded as the mixing length $l_{\text {mix }}$. The lance is fixed at a mixing length of $l_{\text {mix }}=70 \mathrm{~mm}$. A blue oil flame was observed indicating the flame to be premixed. The premixed characteristic of the kerosene flame is verified indirectly by the observation that the $\mathrm{NO}_{\mathrm{x}}$ emissions are of the same order of magnitude as for premixed natural gas flames. Further proof that a premixed flame has been achieved will be shown in Sect. 3.2. Alternatively, natural gas can be supplied far upstream of the burner for perfectly premixed operation. The long mixing section of air and natural gas avoids equivalence ratio fluctuations. The thermal power is varied between 40 and $60 \mathrm{~kW}$. Therefore, the fuel flow rates are in the range of $0.8-1.2 \mathrm{~g} / \mathrm{s}$ and are kept constant for certain thermal powers. In order to adjust the equivalence ratio, the air flow rate is varied between 20 and $32 \mathrm{~g} / \mathrm{s}$ at constant fuel flow rates. As the air mass flow cannot be reduced below $20 \mathrm{~g} / \mathrm{s}$, this leads to a maximum equivalence ratio of $\Phi=0.67$ for a thermal power of $40 \mathrm{~kW}$. The deviations of the flow metering equipment for air and natural gas are around $1 \%$ and for kerosene under $0.25 \%$. The Reynolds number referred to the burner outlet varies from 26,000 to 42,000 .

The test rig has a total of six water-cooled dynamic pressure transducers with an accuracy of $0.00069 \mathrm{kPa}$. Three of these are mounted in the plenum and three in the combustor. This configuration allows reconstruction of the fluctuating acoustic pressure and velocity fields at any given point upstream and downstream of the burner (Paschereit et al. 2002). A detailed description of the test rig is provided by Eckstein (2004) and Stadlmair (2018).

\subsection{Spectrally resolved chemiluminescence}

Spectrally resolved chemiluminescence measurements during stationary operation without acoustic excitation are discussed in the following. The spectrum of the entire flame is obtained after integration over the spatial coordinate of the spectrometer.

The setup for spectrally resolved chemiluminescence measurements is shown schematically in Fig. 1. A SpectraPro 275 imaging spectrometer from Acton Research Cooperation is used for the spectrally resolved investigations. This is a Czerny-Turner monochromator with a focal length of $275 \mathrm{~mm}$ and an aperture ratio of 1:3.8. A grating with 150 grooves per millimetre is used for the studies. Therefore, an observation of approximately $300 \mathrm{~nm}$ of a flame spectrum is possible. Using a UV lens with a focal length of $45 \mathrm{~mm}$ and a maximum aperture of 1:1.8 the image of the flame is focused on the inlet slit of the spectrograph. The slit width is adjusted to $10 \mu \mathrm{m}$. A StreakStar image intensified camera system from LaVision is attached to the spectrometer to record the spectra.

For measurement of a chemiluminescence spectrum with a camera, the intensities are recorded over the individual pixels. To determine the exact wavelengths corresponding to each pixel, an additional calibration measurement is necessary. The spectrum of a mercury arc lamp is recorded using the imaging spectrometer. The measured spectrum contains five distinctive and clearly visible spectral lines. The characteristic wavelengths of the individual spectral lines of the mercury arc lamp are known from Reader et al. (1996). The measured data points can be approximated by a first degree polynomial which represents a conversion rule from the pixel scale to the nm scale.

Furthermore, the imaging spectrometer coupled with the camera has an unknown, wavelength-dependent sensitivity that can be determined by a second calibration. The spectrum of a calibrated halogen lamp is recorded and compared to the reference spectrum of this lamp provided by the manufacturer. Thus, a wavelength-dependent calibration factor can be determined and applied to all measured spectra.

During the spectrally resolved measurements the thermal power was varied between 40 and $60 \mathrm{~kW}$. Flame spectra of 14 equivalence ratios, ranging from 0.53 to 0.8 , were recorded. For each operating point 20 single recorded spectrally resolved images were taken with a resolution of $384 \times$ 286 pixels. An exposure time of $5 \mathrm{~ms}$ was set. Afterwards, 
these images were averaged and evaluated using Matlab. The single spectra were filtered with a Savitzky-Golay filter using fifth degree polynomials. For the approximation of these polynomials 19 interpolation points were used for each polynomial.

Figure 2 shows a typical chemiluminescence spectrum of a lean kerosene flame under atmospheric conditions. The $\mathrm{OH}^{*}, \mathrm{CH}^{*}$ and $\mathrm{C}_{2}$ * peaks are superimposed by a broadband background radiation. To determine the true intensities of the individual radicals, the corresponding background radiation is subtracted from the respective areas in the wavelength ranges of the radicals. For this purpose, the background radiation is linearly interpolated within each radical range. Accordingly, only the area between this linear interpolation and the peak of each radical emission is determined and used for evaluation. These areas are highlighted in Fig. 2. The intensity of the $\mathrm{OH}^{*}$ radical is shown in blue, the intensity of the $\mathrm{CH}^{*}$ radical in red and the intensity of the $\mathrm{C}_{2}$ * radical in yellow.

\subsection{Bandpass-filtered chemiluminescence}

The optical measurement system for bandpass-filtered chemiluminescence investigations is shown schematically in Fig. 1. It consists of a Photron FastCam SAX2 high-speed camera equipped with an image intensifier from Invisible Vision and a silica glass camera lense. An image doubler from LaVision is mounted in front of the camera lens. The image doubler provides a projection of an image pair onto one camera chip.

As already described in Sect. 2.1, the test rig is equipped with six water-cooled $P C B 106 B$ piezoelectric pressure transducers. The data acquisition system comprises

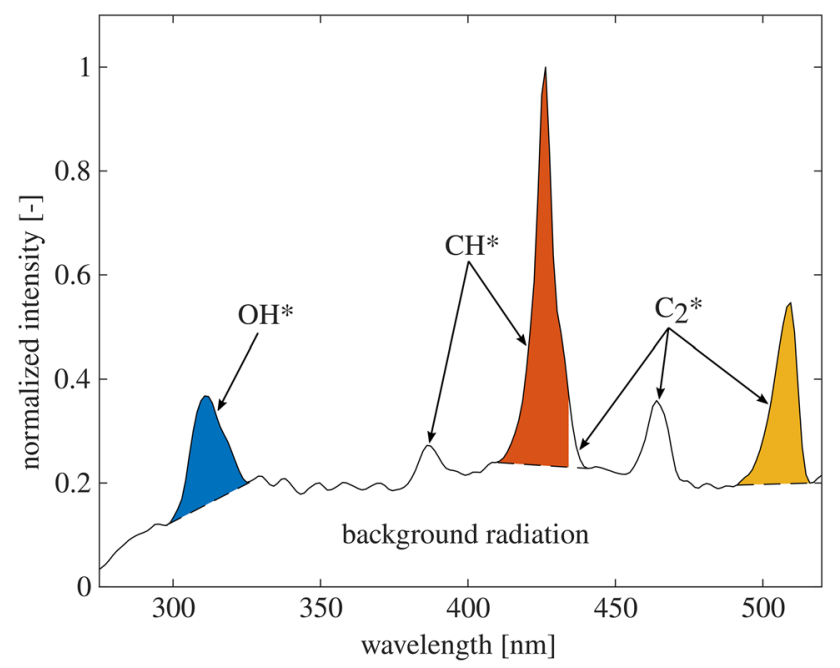

Fig. 2 Typical chemiluminescence spectrum of a lean kerosene flame under atmospheric conditions a measurement computer and a measurement card from National Instruments. In addition to the high-speed images, time series of a total of eight signals are recorded: the pressure curves of the six pressure sensors and the exposure times of the camera and the image intensifier. Images of the entire flame front can be taken through the quartz glass optical access. The focus of the lens was set to the centre plane of the combustion chamber. Furthermore, the frame rate of the camera was set to 2000 frames per second with a resolution of $1024 \times 1024$ pixels. The image intensifier is triggered by the camera. An exposure time of $100 \mu$ s was set. For the stationary measurements, 2000 images were taken and averaged. For the acoustically excited measurements, 6000 images were recorded for each excitation frequency and then grouped according to the phase of the pressure oscillation in 12 equally spaced subintervals resulting in about 500 images for each subinterval.

Two different narrow-band interference filters can be mounted on the image doubler. On one side, an $\mathrm{OH}^{*}$-filter with a maximum transmission of $16.57 \%$ at a characteristic wavelength of $309.65 \mathrm{~nm}$ and a full width at half maximum of $10.2 \mathrm{~nm}$ is attached. On the other side, a $\mathrm{CH}^{*}$-filter with a maximum transmission of $48.63 \%$ at $431.39 \mathrm{~nm}$ and a full width at half maximum of $10.6 \mathrm{~nm}$ is installed. In this way, $\mathrm{OH}^{*}$ and $\mathrm{CH}^{*}$ chemiluminescence can be recorded simultaneously with the image doubler. The wavelengths transmitted by the $\mathrm{OH}^{*}$-filter and the $\mathrm{CH}^{*}$-filter correspond to the emission intensity of $\mathrm{OH}^{*}$ and $\mathrm{CH}^{*}$ superimposed by the broadband background radiation, as shown in Fig. 2 .

As will be shown in Sect. 3.1, the background radiation has no influence on the monotonic relationship between the $\mathrm{CH}^{*} / \mathrm{OH}^{*}$ ratio and the equivalence ratio for kerosene combustion. For this reason, the contribution of the broadband background radiation in the recorded spectral band is no longer taken into account in further evaluation.

The post-processing of all flame images for evaluating bandpass-filtered chemiluminescence is shown in Fig. 3. The image pair is first divided into two separate images for $\mathrm{OH}^{*}$ and $\mathrm{CH}^{*}$. After averaging the $\mathrm{OH}^{*}$ and $\mathrm{CH}^{*}$ images individually, an image distortion correction procedure is applied. An additional reference target is placed in the centre plane of the combustion chamber and is imaged through both eyes of the image doubler. A transformation is applied to both images using Matlab, which takes the perspective distortion into account so that the two images coincide. Due to the stereoscopic acquisition with the image doubler, a shift in line-of-sight direction of the target leads to a shift of the centre position of the virtual image in horizontal direction. A maximum displacement of the centre of the virtual image of $+/-2 \mathrm{~mm}$ in the horizontal direction is determined. Distortion correction is being done without the interference filters. Furthermore, the single images are filtered with a threshold value of $10 \%$ of the maximum chemiluminescence intensity 

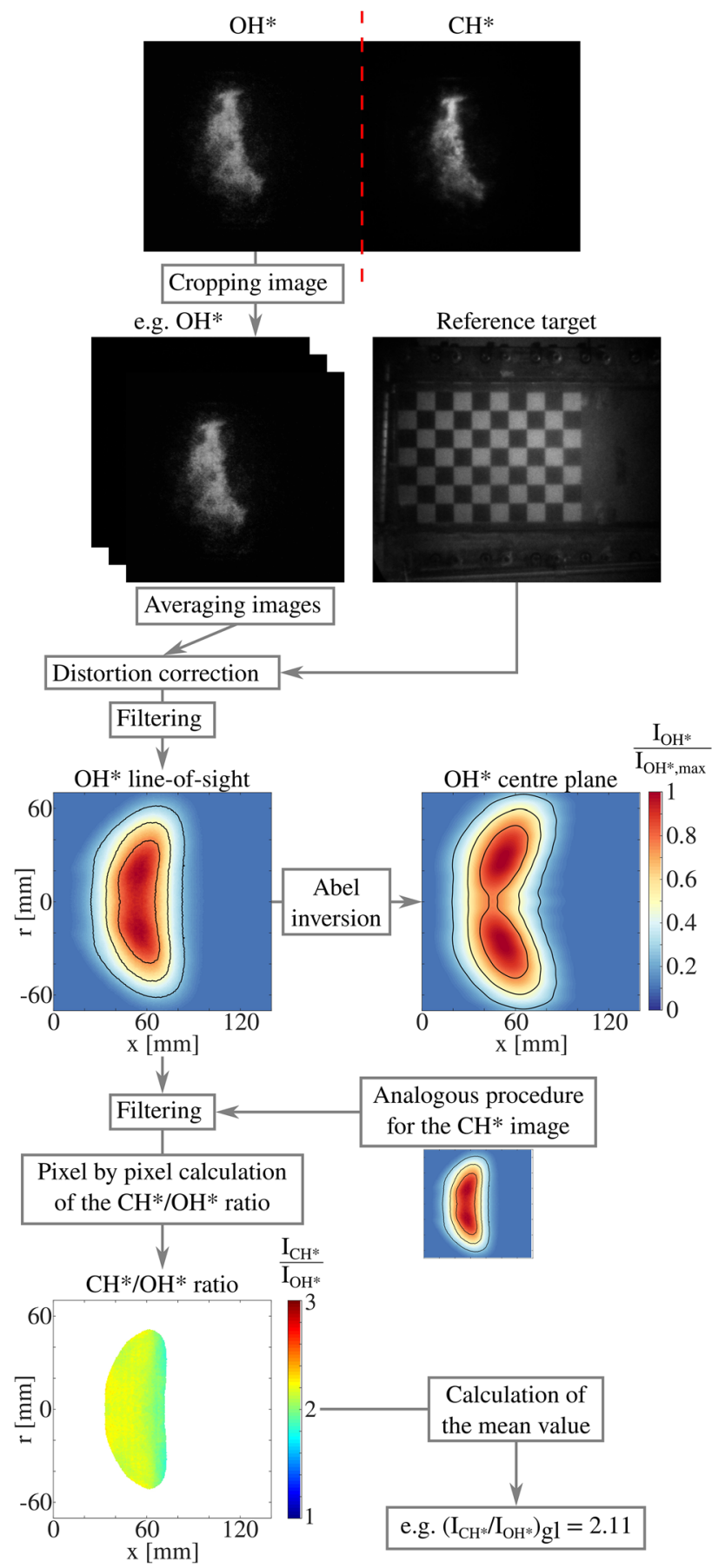

Fig. 3 Post-processing of flame images for evaluating bandpass-filtered chemiluminescence

and isolines with $25 \%, 50 \%$ and $75 \%$ of the maximum intensity are computed. These isolines are represented by contour plots as shown in Fig. 3. The distortion corrected images represent the integrated line-of-sight intensity distribution. Assuming a rotationally symmetric flame, the intensity distribution in the centre plane can be calculated using an Abel inversion. Therefore, an Abel inversion using a Fourier method with fifteen terms is applied (Pretzler et al. 1992). This procedure is carried out analogously for the $\mathrm{CH}^{*}$ data. For the calculation of the $\mathrm{CH}^{*} / \mathrm{OH}^{*}$ ratio the $\mathrm{CH}^{*}$ and $\mathrm{OH}^{*}$ images are filtered again to ensure a minimum intensity of $50 \%$ of the respective maximum chemiluminescence intensity. The local $\mathrm{CH}^{*} / \mathrm{OH}^{*}$ ratio is then calculated for each pixel where the intensity of both $\mathrm{CH}^{*}$ and $\mathrm{OH}^{*}$ is at least $50 \%$ of the respective maximum chemiluminescence intensity. The global mean value $\left(I_{\mathrm{CH}} * / I_{\mathrm{OH}} *\right)_{\mathrm{gl}}$ can be calculated as the average value of the local $\mathrm{CH}^{*} / \mathrm{OH}^{*}$ ratio for each operating point. Moreover, the deviation of the local $\mathrm{CH}^{*} / \mathrm{OH}^{*}$ ratio from the global mean $\mathrm{CH}^{*} / \mathrm{OH}^{*}$ ratio of a single operating point is defined as follows:

$e_{\mathrm{rel}}(\mathrm{x}, \mathrm{r})=\frac{\left|\frac{I_{\mathrm{CH}} *(x, r)}{I_{\mathrm{OH}}(x, r)}-\left(\frac{I_{\mathrm{CH}} *}{I_{\mathrm{OH}} *}\right)_{g l}\right|}{\left(\frac{I_{\mathrm{CH}^{*}}}{I_{\mathrm{OH}^{*}}}\right)_{g l}}$

For the acoustically excited experiments a synchronisation of pressure and image data is performed. Firstly, the points in time are identified at which an image was recorded. The signals of the high-speed camera and the image intensifier are used for this purpose. Subsequently, the phase of the oscillation can be assigned to the recording times of the individual images based on the pressure data. The single images are referred to the phase of the pressure oscillation at the reference sensor according to Fig. 1. The phase of the oscillation at the position of the reference sensor is calculated using the Hilbert transformation. The phase, which can assume values between $-\pi$ and $\pi$, is divided into 12 subintervals of equal size. In this way, each image with the corresponding phase of oscillation can be assigned to a subinterval.

For the images grouped in this way, average images can then be calculated separately for each group. Afterwards, the ratio of $\mathrm{CH}^{*} / \mathrm{OH}^{*}$ is determined pixel by pixel for each group, resulting in 12 phase-averaged images over the pulsation cycle. For all frequencies, the global mean values of every $\mathrm{CH}^{*} / \mathrm{OH}^{*}$ image are calculated from the 12 phaseaveraged images. Applying the calibration chart, which will be presented in Sect. 3.2, a phase-averaged global equivalence ratio $\langle\Phi\rangle$ can then be determined for each subinterval. The mean value of the corresponding phase interval is assigned to the calculated global equivalence ratio as phase $\varphi$.

In an acoustically excited flow the equivalence ratio can be divided into three parts: the time-averaged (mean) $\bar{\Phi}$, a random $\tilde{\Phi}$ and a deterministic $\Phi^{\prime}$ component (Lieuwen 2013), resulting in:

$\Phi=\bar{\Phi}+\tilde{\Phi}+\Phi^{\prime}$ 
Since only time-averaged values are considered within this study, it can be assumed that the random component is averaged out. For this reason, the random component is neglected in the following. The deterministic part is then calculated as follows:

$\Phi^{\prime}=\langle\Phi\rangle-\bar{\Phi}$

$\Phi^{\prime}$ describes the global equivalence ratio fluctuation, $\langle\Phi\rangle$ is the phase-averaged global equivalence ratio and $\bar{\Phi}$ is the time-averaged global equivalence ratio. The equivalence ratio fluctuation is approximated by the following Fourier approach:

$\frac{\langle\Phi\rangle}{\bar{\Phi}}(\varphi)=a \cdot \cos \left(\varphi-\varphi_{k}\right)+b$

Here, $a$ describes the amplitude of the oscillation, $\varphi_{\mathrm{k}}$ the phase shift and $b$ a scaling factor for the vertical displacement. The unknown constants $a, \varphi_{\mathrm{k}}$ and $b$ are approximated using a least square method.

\section{Results}

The results of this study are shown and discussed in the following subsections. Firstly, the results of the spectrally resolved investigation are presented. As already mentioned in Sect. 2.2 the chemiluminescence from $\mathrm{OH}^{*}, \mathrm{CH}^{*}$ and $\mathrm{C}_{2} *$ is superimposed by a broadband background radiation, which must be taken into account in the evaluation procedure. The subtraction of the broadband background radiation from the respective chemiluminescence intensities is referred to as background correction in the following. The focus of the spectrally resolved measurements is on the influence of the background correction on the correlation between different intensity ratios of the species $\mathrm{OH}^{*}, \mathrm{CH}^{*}$ and $\mathrm{C}_{2} *$ and the equivalence ratio. Only the global spectral characteristics of the different chemiluminescence species are considered here.

Secondly, the results of the bandpass-filtered chemiluminescence measurement are discussed. Here, the applicability of the measurement technique during acoustic excitation is examined in more detail.

\subsection{Global equivalence ratio from spectrally resolved chemiluminescence}

Firstly, the intensity ratios with background correction are examined in detail. Lauer (2011) and Muruganandam et al. (2005) have shown that the $\mathrm{CH} * / \mathrm{OH}^{*}$ ratio is only a function of the equivalence ratio for the combustion of natural gas.

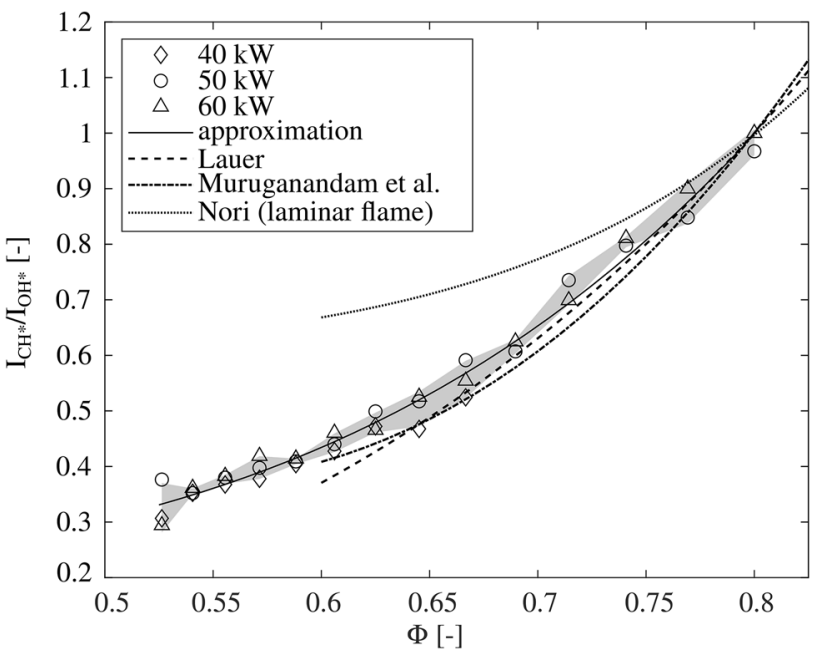

Fig. 4 The dependence of the $\mathrm{CH}^{*} / \mathrm{OH}^{*}$ chemiluminescence ratio on the equivalence ratio $\Phi$ with background correction for the combustion of natural gas under atmospheric conditions. The shaded region indicates the standard deviation. Reference results for the combustion of natural gas from Lauer (2011), Muruganandam et al. (2005) and Nori (2008) are presented additionally. Data are normalized by their value at $\Phi=0.8$

Figure 4 shows the relationship of the $\mathrm{CH}^{*} / \mathrm{OH}^{*}$ ratio and the equivalence ratio for the combustion of natural gas under atmospheric conditions. The $\mathrm{CH} * / \mathrm{OH}^{*}$ ratio is plotted against the equivalence ratio for various thermal powers. In addition, reference results from Lauer (2011), Muruganandam et al. (2005) and Nori (2008) are presented. For comparison, all data are normalized by their value at $\Phi=0.8$. Lauer (2011) used the TD1 swirl burner. It consists of a tangential swirl generator, a conical nozzle and a cylindric centre body. Muruganandam et al. (2005) conducted their measurements using a swirl burner with a swirling inlet section and swirl vanes housed in a tube. Nori (2008) investigated a laminar jet flame. It can be seen that the $\mathrm{CH}^{*} / \mathrm{OH}^{*}$ ratio has a monotonic dependence on the equivalence ratio within the investigated equivalence ratio range. The $\mathrm{CH}^{*} / \mathrm{OH}^{*}$ ratio increases with increasing equivalence ratio. The $\mathrm{CH}^{*} /$ $\mathrm{OH}^{*}$ ratio is almost independent of the thermal power. The measured data points can be approximated by an exponential approach. The approximation provides a precise correlation between the $\mathrm{CH}^{*} / \mathrm{OH}^{*}$ ratio and the equivalence ratio. Thus the $\mathrm{CH}^{*} / \mathrm{OH}^{*}$ ratio represents a very robust measurement for determining the equivalence ratio. The presented results generally agree with results from Lauer (2011) and Muruganandam et al. (2005). In contrast, the laminar jet flame shows a lower sensitivity of the $\mathrm{CH}^{*} / \mathrm{OH}^{*}$ ratio to the equivalence ratio in the investigated range. This observation was also reported by Nori (2008). Therefore, it can be assumed that the measurement setup used has been calibrated and adjusted appropriately and thus provides reliable results. 
In the following, different ratios of chemiluminescence species and their relation to the equivalence ratio are examined for lean premixed kerosene combustion. In contrast to natural gas combustion, the lean combustion of kerosene results in several ratios, since $\mathrm{C}_{2} *$ radicals can also be measured.

Figure 5 presents chemiluminescence ratios for the three species, specifically $\mathrm{CH}^{*} / \mathrm{OH}^{*}, \mathrm{C}_{2} * / \mathrm{CH}^{*}$ and $\mathrm{C}_{2} * / \mathrm{OH}^{*}$, under atmospheric conditions. The ratios are plotted over the equivalence ratio for different thermal powers. The different thermal powers are represented by various symbols. In all three cases, there is a monotonous relationship between the equivalence ratio and the chemiluminescence ratios within the investigated range. All three ratios increase with increasing equivalence ratio and are almost independent of the thermal power and thus also of the strain rate. The $\mathrm{CH}^{*} /$ $\mathrm{OH}^{*}$ ratio shows a linear relationship to the equivalence ratio, whereas the $\mathrm{C}_{2} * / \mathrm{CH}^{*}$ and $\mathrm{C}_{2}{ }^{*} / \mathrm{OH}^{*}$ ratio can better be approximated by a power law. $\mathrm{C}_{2} * / \mathrm{OH}^{*}$ shows the greatest sensitivity to the equivalence ratio.

The same intensity ratios are investigated without background correction in the following. Figure 6 shows the $\mathrm{CH}^{*} /$ $\mathrm{OH}^{*}, \mathrm{C}_{2} * / \mathrm{CH}^{*}$ and $\mathrm{C}_{2} * / \mathrm{OH}^{*}$ ratios over the equivalence ratio without background correction for the combustion of kerosene. Moreover, the $\mathrm{CH}^{*} / \mathrm{OH}^{*}$ ratio without background correction is presented for the combustion of natural gas. It is noted that the $\mathrm{CH}^{*} / \mathrm{OH}^{*}$ ratio without background correction does not show a monotonous trend for natural gas combustion. In contrast to the kerosene flame, the natural gas flame is observed to attach to the combustion chamber

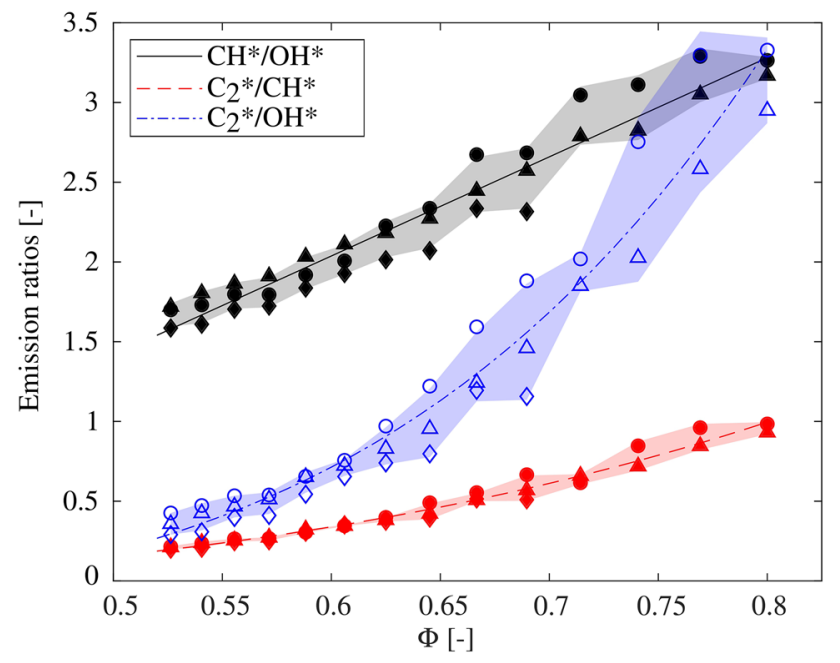

Fig. 5 The dependence of different chemiluminescence ratios on the equivalence ratio $\Phi$ with background correction for the combustion of kerosene under atmospheric conditions. Various thermal powers are marked with symbols (diamond: $40 \mathrm{~kW}$, circle: $50 \mathrm{~kW}$, triangle: $60 \mathrm{~kW}$ ). Shaded regions indicate standard deviations

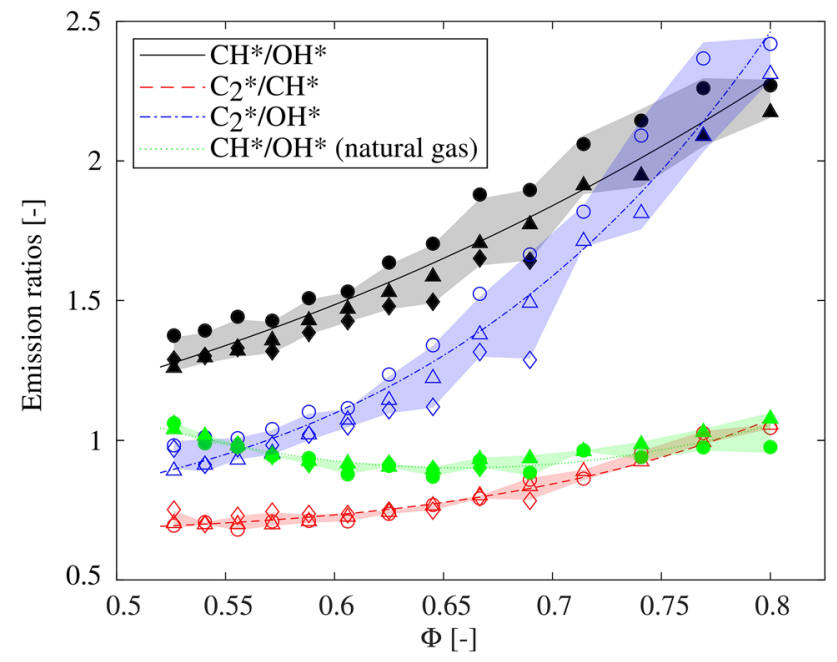

Fig. 6 The dependence of different chemiluminescence ratios on the equivalence ratio $\Phi$ without background correction for the combustion of kerosene and natural gas under atmospheric conditions. Various thermal powers are marked with symbols (diamond: $40 \mathrm{~kW}$, circle: $50 \mathrm{~kW}$, triangle: $60 \mathrm{~kW}$ ). Shaded regions indicate standard deviations

walls for equivalence ratios below 0.65 . Wall interactions may influence the chemiluminescence signals, so care has to be taken when interpreting the $\mathrm{CH} * / \mathrm{OH}^{*}$ ratios in this range.

For the combustion of kerosene, all three chemiluminescence ratios show a monotonous behaviour without background correction. With increasing equivalence ratio all three ratios increase. Similarly to the results with background correction, the $\mathrm{C}_{2} * / \mathrm{CH}^{*}$ and $\mathrm{C}_{2} * / \mathrm{OH}^{*}$ ratios show an exponential trend. While the $\mathrm{CH}^{*} / \mathrm{OH}^{*}$ ratio with background correction was approximated by a first order polynomial, the ratio without background correction can be better approximated by a power law. $\mathrm{The}_{2} \mathrm{C}_{2} / \mathrm{OH}^{*}$ shows the greatest sensitivity to the equivalence ratio. The slope sensitivity of all three ratios is lower compared to the results with background correction. Especially in the lean range the $\mathrm{C}_{2} * / \mathrm{CH}^{*}$ ratio shows hardly any sensitivity to the equivalence ratio. In summary, the $\mathrm{CH}^{*} / \mathrm{OH}^{*}$ and the $\mathrm{C}_{2}{ }^{*} / \mathrm{OH}^{*}$ ratios seem promising for equivalence ratio sensing. Since the $\mathrm{CH}^{*} / \mathrm{OH}^{*}$ ratio is the standard choice for equivalence ratio sensing in natural gas flames, this ratio is also chosen for the following bandpass filtered chemiluminescence measurements.

\subsection{Equivalence ratio from bandpass-filtered chemiluminescence}

To assess the transmission behaviour of the measurement system as well as the sensitivity of the camera chip, the relationship of the $\mathrm{CH}^{*} / \mathrm{OH}^{*}$ ratio to the equivalence ratio during stationary operation is first determined. Figure $7 \mathrm{a}$ shows $\mathrm{CH}^{*}$ and $\mathrm{OH}^{*}$ line-of-sight images of the flame for 

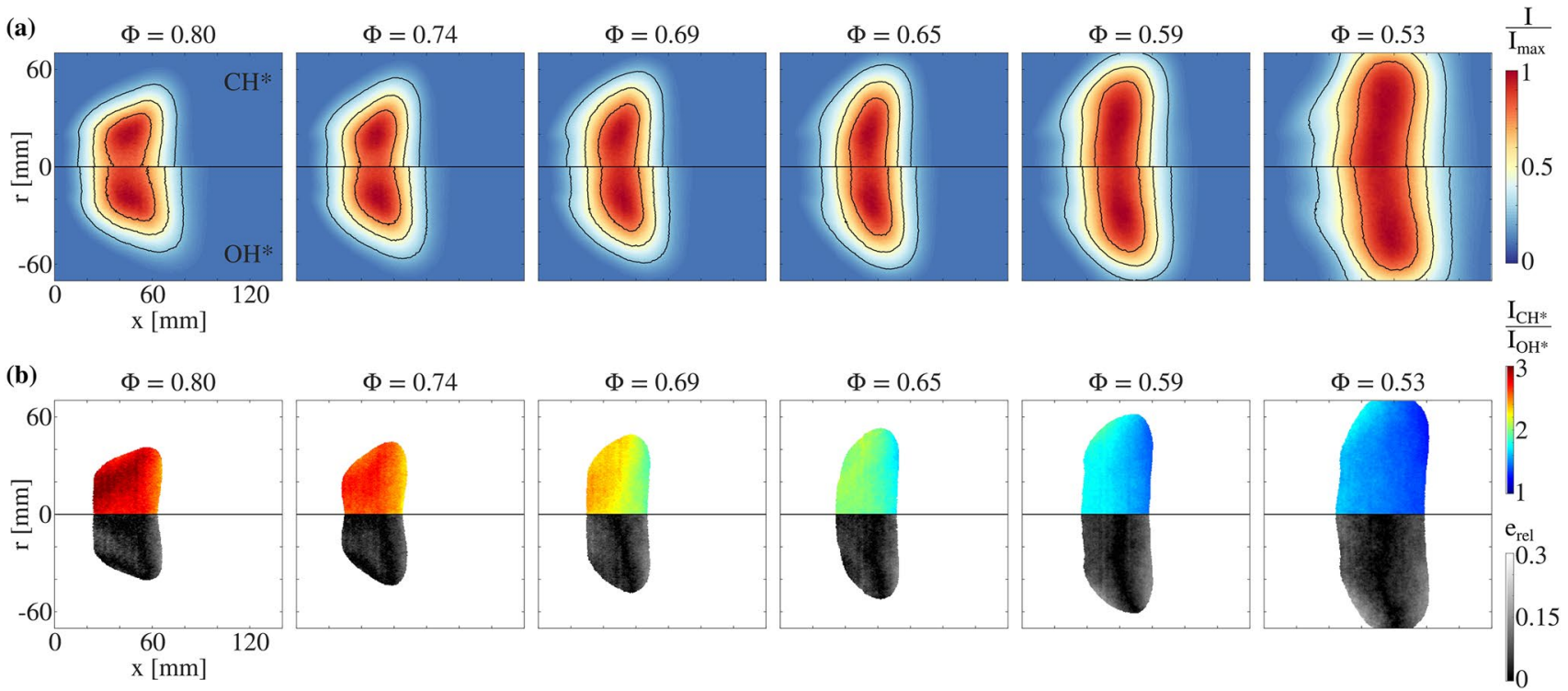

Fig. 7 a Locally resolved $\mathrm{CH}^{*}$ and $\mathrm{OH}^{*}$ chemiluminescence intensity over the flame front for kerosene combustion at a thermal power of $50 \mathrm{~kW}$, line-of-sight data. The solid black lines represent the $75 \%$, $50 \%$ and $25 \%$ isolines of the chemiluminescence intensity. b Locally

six different equivalence ratios ranging from $\Phi=0.8$ to $\Phi=0.53$. Owing to the rotational symmetry of the flame, only half of the image is presented. The upper half of the image shows the $\mathrm{CH}^{*}$ image, the lower half the corresponding $\mathrm{OH}^{*}$ image. All images are normalized to their maximum value. Based on the contour plots, it can be seen that $\mathrm{CH}^{*}$ appears slightly before $\mathrm{OH}^{*}$. This shift in the $\mathrm{CH}^{*}$ and $\mathrm{OH}^{*}$ images may be due to the stereoscopic imaging as mentioned in Sect. 2.3.

Based on the local intensity distribution of the two images, the spatially resolved $\mathrm{CH}^{*} / \mathrm{OH}^{*}$ ratio can be calculated. The upper half of Fig. $7 \mathrm{~b}$ presents the resulting $\mathrm{CH}^{*} /$ $\mathrm{OH}^{*}$ line-of-sight distribution. A homogeneous distribution of the $\mathrm{CH}^{*} / \mathrm{OH}^{*}$ ratio and thus a homogeneous distribution of the equivalence ratio over the entire flame can be observed. It can also be seen, that the local $\mathrm{CH}^{*} / \mathrm{OH}^{*}$ ratio decreases with decreasing equivalence ratio. In addition, the relative deviation of the local to the mean $\mathrm{CH}^{*} / \mathrm{OH}^{*}$ ratio for each operating point is shown in the lower half of the image.

Only small deviations of the local to the mean $\mathrm{CH}^{*} / \mathrm{OH}^{*}$ ratio are observed across the entire flame. Most of the flame shows a local deviation of less than $5 \%$ from the mean value. The highest deviations of nearly $20 \%$ are found only in very small areas at the edge of the flame. A uniform distribution of the equivalence ratio across the entire flame can therefore be assumed. Thus, the global analysis of the flame chemiluminescence, as carried out in the spectrally resolved investigations, seems to be justified. It can also be stated that resolved $\mathrm{CH}^{*} / \mathrm{OH}^{*}$ distribution and deviation of the local $\mathrm{CH}^{*} / \mathrm{OH}^{*}$ ratio from the mean value according to $\mathrm{Eq} .1$ over the flame front, line-of-sight data

the subject of the investigation was a well premixed system, as already indicated by the low $\mathrm{NO}_{\mathrm{x}}$ emissions.

Figure $8 \mathrm{a}$ shows the $\mathrm{CH}^{*}$ and $\mathrm{OH}^{*}$ intensity distribution in the centre plane for the same operating points as shown in Fig. 7. Again, it can be seen that $\mathrm{CH}^{*}$ appears slightly before $\mathrm{OH}^{*}$. Figure $8 \mathrm{~b}$ presents the $\mathrm{CH} / \mathrm{OH}^{*}$ distribution in the centre plane as well as the relative deviation of the local to the mean $\mathrm{CH}^{*} / \mathrm{OH}^{*}$ ratio. The same behaviour as in the line-of-sight data can be seen here. As the equivalence ratio decreases, the $\mathrm{CH}^{*} / \mathrm{OH}^{*}$ ratio also decreases. Furthermore, a homogeneous distribution of the equivalence ratio over the entire flame can be observed. The local ratio never deviates more than $20 \%$ from the average value, and this only in small areas. Hence, this measurement method can also be used to obtain the equivalence ratio of the flame in the combustor centre plane.

Figure 9 presents the relationship between the global $\mathrm{CH}^{*} / \mathrm{OH}^{*}$ ratio and the equivalence ratio for the line-of-sight and centre plane data. Also, a clear correlation between the $\mathrm{CH}^{*} / \mathrm{OH}^{*}$ ratio and the equivalence ratio can be seen for the bandpass-filtered measurements. The $\mathrm{CH}^{*} / \mathrm{OH}^{*}$ ratio increases monotonically with increasing equivalence ratio. The thermal power has no influence on this ratio. Furthermore, the $\mathrm{CH}^{*} / \mathrm{OH}^{*}$ ratio in the centre plane is nearly identical to the line-of-sight ratio. Based on these results, a calibration curve can be derived representing a functional correlation between the global $\mathrm{CH}^{*} / \mathrm{OH}^{*}$ ratio and the equivalence ratio only. 
(a)
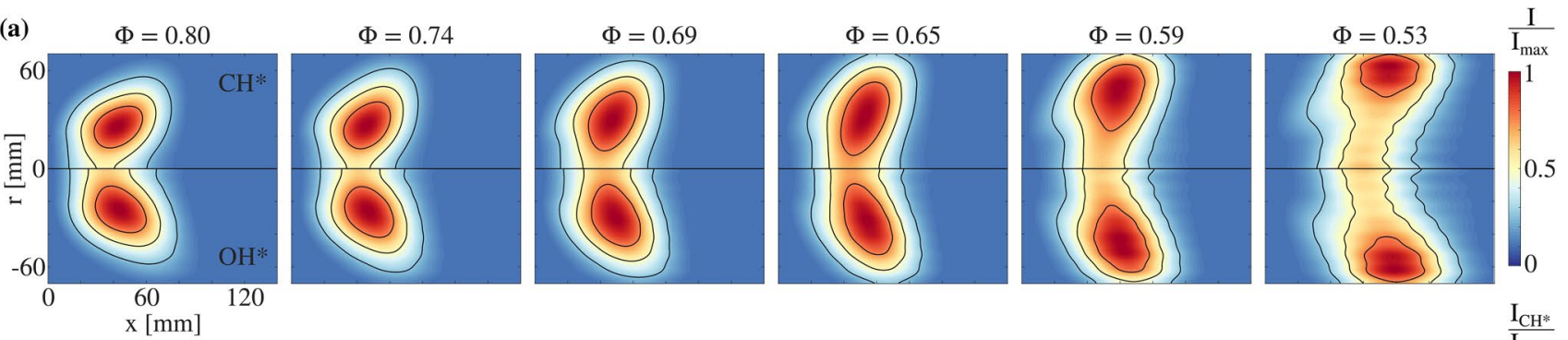

(b)

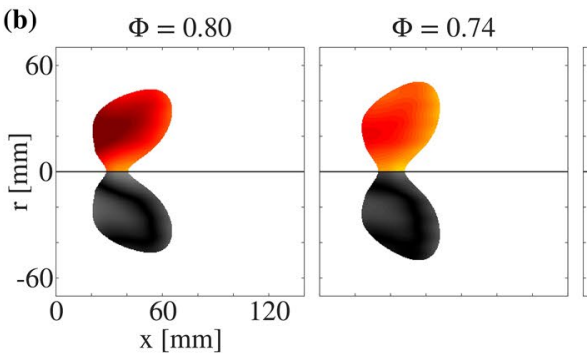

Fig. 8 a Locally resolved $\mathrm{CH}^{*}$ and $\mathrm{OH}^{*}$ chemiluminescence intensity in the combustor centre plane for kerosene combustion at a thermal power of $50 \mathrm{~kW}$. The solid black lines represent the $75 \%, 50 \%$ and
$25 \%$ isolines of the chemiluminescence intensity. b Locally resolved $\mathrm{CH}^{*} / \mathrm{OH}^{*}$ distribution and deviation of the local $\mathrm{CH}^{*} / \mathrm{OH}^{*}$ ratio from the mean value according to Eq. 1 in the combustor centre plane

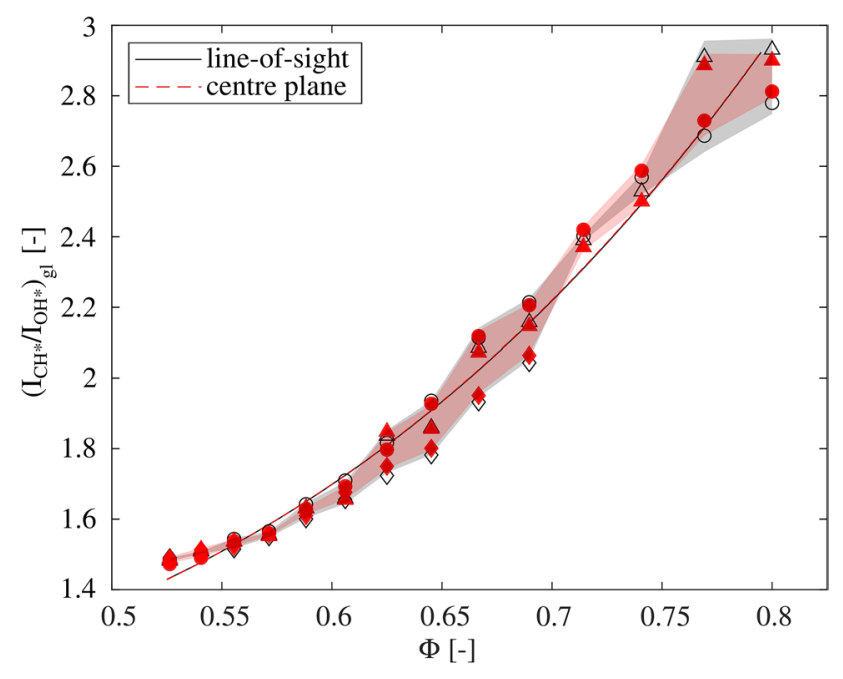

Fig. 9 The dependence of the $\mathrm{CH}^{*} / \mathrm{OH}^{*}$ chemiluminescence ratio on the equivalence ratio $\Phi$ for the combustion of kerosene under atmospheric conditions. Various thermal powers are marked with symbols (diamond: $40 \mathrm{~kW}$, circle: $50 \mathrm{~kW}$, triangle: $60 \mathrm{~kW}$ ). Shaded regions indicate standard deviations

\subsection{Equivalence ratio fluctuations during acoustic excitation}

By way of example, the procedure presented in Sect. 3.2 is applied to one operating point with acoustic excitation. An equivalence ratio of $\Phi=0.67$ and a thermal power of $50 \mathrm{~kW}$ are selected as a nominal operating point. Figure 10a shows phase-resolved $\mathrm{CH}^{*}$ and $\mathrm{OH}^{*}$ line-of-sight images of the flame for six different oscillation phases ranging from $\varphi=15^{\circ}$ to $\varphi=315^{\circ}$. Owing to the rotational symmetry of the flame, only half of the image is presented. The upper half of the image shows the $\mathrm{CH}^{*}$ chemiluminescence intensity, the lower half the corresponding $\mathrm{OH}^{*}$ image. All images are normalized to the maximum value over the oscillation. Analogously, Fig. 10b shows the same oscillation cycle in the combustor centre plane. These images were calculated using an Abel inversion according to Fig. 3. Furthermore, Fig. 11 shows the evolution of the phase-averaged equivalence ratio during two excitation periods for an excitation frequency of $f=100 \mathrm{~Hz}$.

The results of the line-of-sight measurement are shown as well as the calculated equivalence ratio fluctuation in the centre plane. Furthermore, the corresponding approximations according to Eq. 4 are presented. The global equivalence ratio features only relatively weak fluctuations. The normalized equivalence ratio only assumes values between 0.97 and 1.02 during one excitation period. It can also be seen that the equivalence ratio in the centre plane takes on almost the same values as the line-of-sight integrated equivalence ratio. Of note is the low amplitude of the oscillation of only $2 \%$. This might be attributed to the long mixing length of $70 \mathrm{~mm}$ between nozzle outlet and combustion chamber inlet. Furthermore, dispersive effects during mixture preparation could lead to a reduction of equivalence ratio fluctuations.

Figure 12 shows the relative magnitude of the equivalence ratio perturbation normalized by the acoustic forcing 

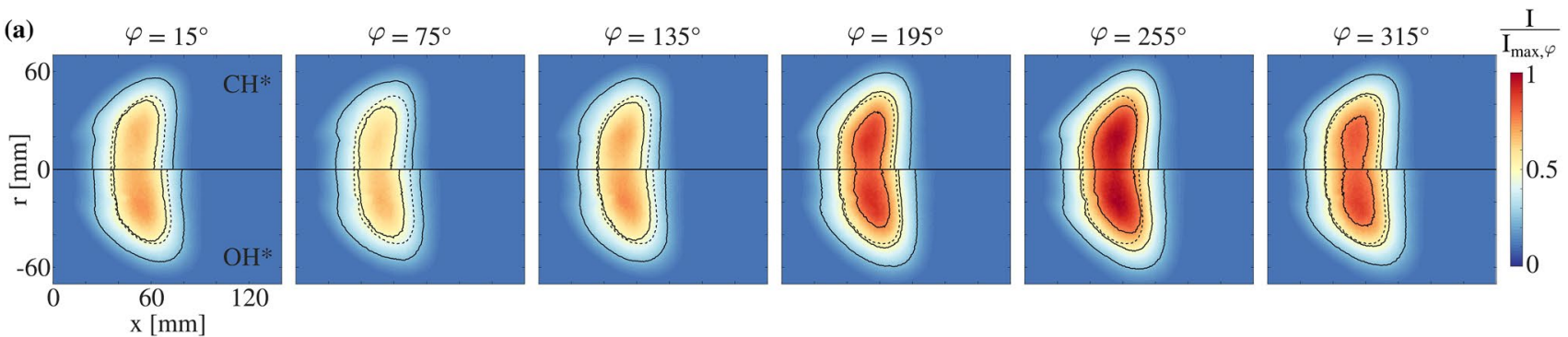

(b)

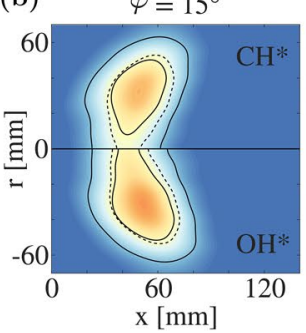

$\varphi=75^{\circ}$
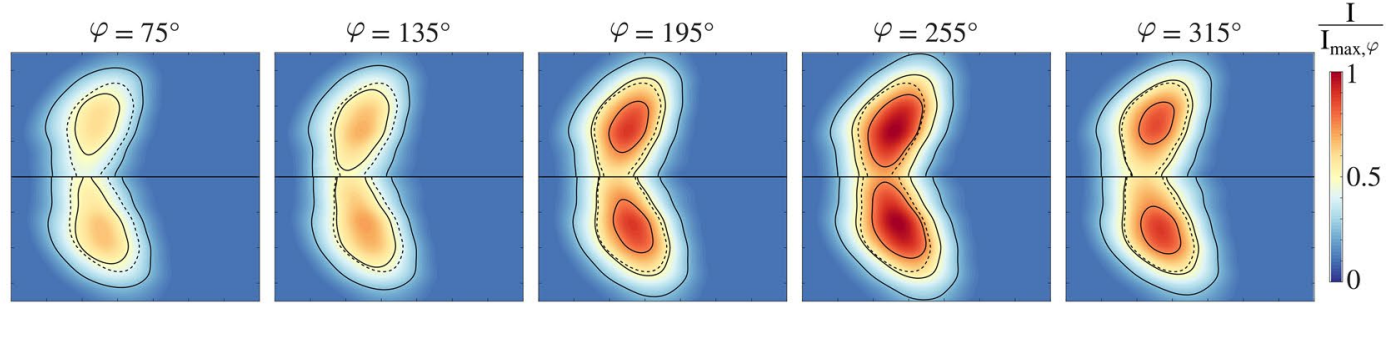

Fig. 10 a Phase-resolved $\mathrm{CH}^{*}$ and $\mathrm{OH}^{*}$ chemiluminescence intensity for kerosene combustion, line-of-sight data. b Phase-resolved $\mathrm{CH}^{*}$ and $\mathrm{OH}^{*}$ chemiluminescence intensity for kerosene combustion in the combustor centre plane. The excitation frequency is set to $f=100 \mathrm{~Hz}$. The solid black lines represent the $75 \%, 50 \%$ and $25 \%$

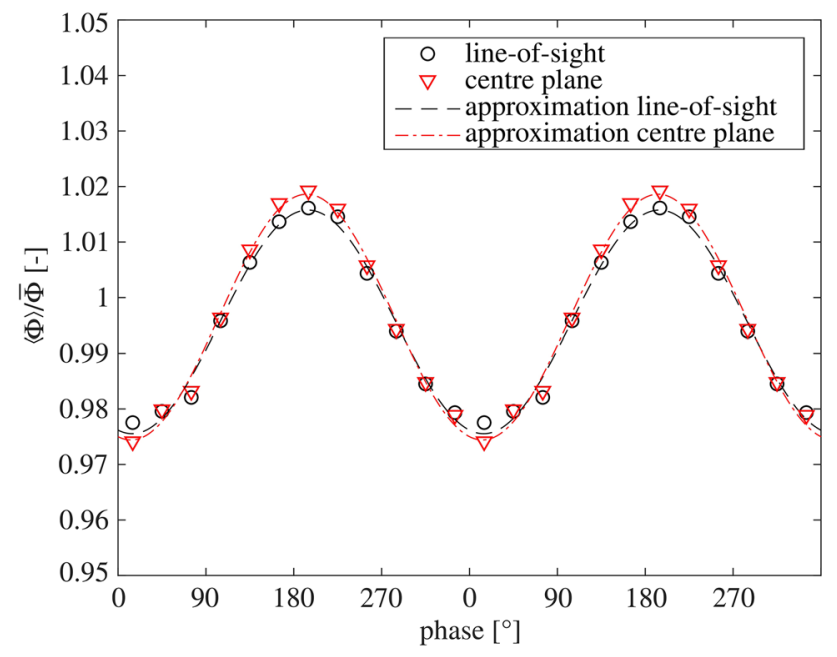

Fig. 11 Evolution of the equivalence ratio during two excitation periods for an excitation frequency of $f=100 \mathrm{~Hz}$

magnitude $|\hat{\mathrm{u}}| / \mathrm{U}$ at the burner outlet in the frequency range from $f=60 \mathrm{~Hz}$ to $f=300 \mathrm{~Hz}$. The magnitude of the lineof-sight integrated equivalence ratio oscillation and the magnitude of the oscillation in the centre plane are shown. The global equivalence ratio fluctuations are determined based on Eq. 3. The bulk velocity $U$ and the amplitude of the acoustic velocity fluctuation $|\hat{\mathrm{u}}|$ are calculated from the total air mass flow and the acoustic field reconstruction respectively. A sufficiently strong forcing of the air mass flow is observed over the entire investigated range. The isolines of the chemiluminescence intensity. The images for $\varphi=15^{\circ}$, $\varphi=75^{\circ}$ and $\varphi=135^{\circ}$ do not show values over $75 \%$ of the maximum value. The dashed black line shows the $50 \%$ isoline of the timeaveraged mean image

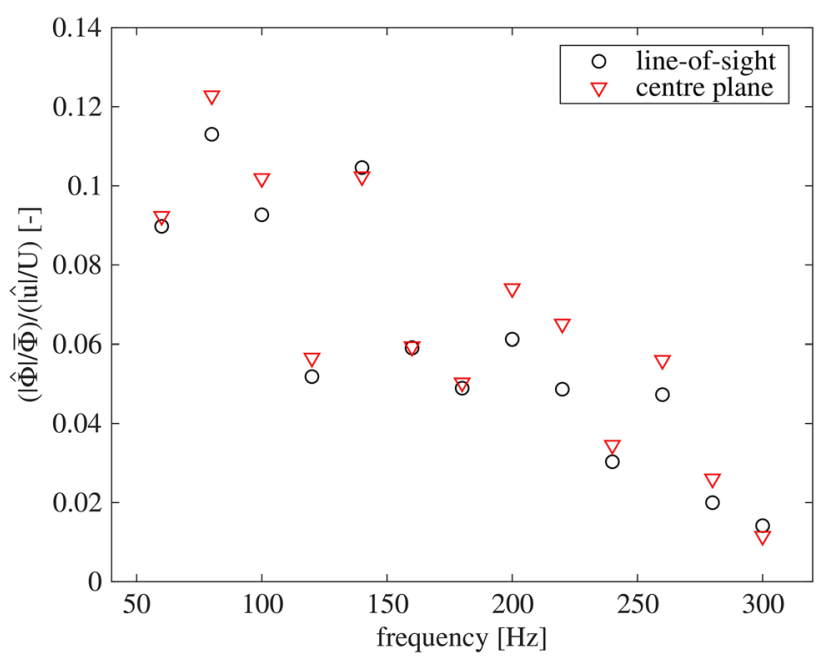

Fig. 12 Relative magnitude of the equivalence ratio oscillation, normalized by the acoustic forcing magnitude $|\hat{u}| / \mathrm{U}$ at the burner outlet

relative magnitude of the acoustic forcing is around $15 \%$ over the entire range. Over the entire investigated range, the relative equivalence ratio fluctuations in the centre plane are almost equal to the line-of-sight integrated perturbations. The strongest equivalence ratio fluctuations are observed at excitation frequencies below $150 \mathrm{~Hz}$. The maximum fluctuation is found at an excitation frequency of $f=80 \mathrm{~Hz}$ with values just above 0.1 . It can clearly be seen that the equivalence ratio fluctuations decrease with increasing excitation frequency. At an excitation frequency of $f=300 \mathrm{~Hz}$, 
almost no equivalence ratio fluctuations can be observed. Here, the value of the relative equivalence ratio perturbation normalized by the acoustic velocity fluctuation is only 0.012 in the centre plane. This observation indicates that equivalence ratio fluctuations in spray combustion only play a major role for low excitation frequencies, which is in line with expectations. This low-pass behaviour has also been reported for partially premixed natural gas combustion by Freitag (2009). It can be explained by the short wavelength of the convectively transported equivalence ratio oscillation. In combination with the spatial mixing in the turbulent flow field between fuel injection and flame, this leads to a strong dispersion of the equivalence ratio wave.

\section{Summary and conclusion}

This paper presents an optical measurement method for the quantification of equivalence ratio fluctuations in spray combustion based on measurement of the $\mathrm{OH}^{*}$ and $\mathrm{CH}^{*}$ chemiluminescence of the flame. The bandpass-filtered chemiluminescence technique developed in previous studies (Lauer 2011) is significantly simplified, as the chemiluminescence species $\mathrm{OH}^{*}$ and $\mathrm{CH}^{*}$ do not need to be background corrected for kerosene combustion.

Firstly, spectrally resolved measurements of kerosene combustion were carried out during stationary operation to identify the influence of the broadband background radiation on the relationship between the ratio of different chemiluminescence species and the equivalence ratio. It was found that the ratios of $\mathrm{CH}^{*} / \mathrm{OH}^{*}, \mathrm{C}_{2} * / \mathrm{OH}^{*}$ and $\mathrm{C}_{2} * / \mathrm{CH}^{*}$, both with and without background correction, are monotonically related to the equivalence ratio within the investigated range. All three ratios increase with increasing equivalence ratio. The overall mass flow rates had almost no influence on these ratios.

Subsequently, a measurement method for the determination of equivalence ratio fluctuations in spray combustion during acoustic excitation was developed based on these findings. For this purpose, an image doubler was mounted in front of an intensified high speed camera and fitted with two bandpass filters. This allowed simultaneous acquisition of the $\mathrm{OH}^{*}$ and $\mathrm{CH}^{*}$ chemiluminescence of the flame on one camera chip. It was shown that the ratio of the two intensity images is directly proportional to the equivalence ratio. Using a first determined calibration chart, the global equivalence ratio was calculated in a phase-resolved manner during acoustic excitation. Equivalence ratio fluctuations were investigated in a frequency range from $f=60 \mathrm{~Hz}$ to $f=300 \mathrm{~Hz}$ at a nominal equivalence ratio of $\Phi=0.67$ and a thermal power of $50 \mathrm{~kW}$. It was observed that equivalence ratio fluctuations are particularly dominant in the frequency range below $200 \mathrm{~Hz}$. For higher frequencies the fluctuations decrease significantly and are scarcely significant.

Further investigations are planned to determine the influence of equivalence ratio fluctuations for additional operating points. As the axial position of the nozzle can be varied, the influence of the degree of premixing on the magnitude of equivalence ratio fluctuations will also be investigated.

Acknowledgements The investigations were conducted as part of the joint research program ECOFlex-turbo in the frame of AG Turbo. The authors gratefully acknowledge GE Power and AG Turbo for their support.

Funding Open Access funding enabled and organized by Projekt DEAL. The work was supported by GE Power and the Federal Ministry for Economic Affairs and Energy (BMWi) as per resolution of the German Federal Parliament under Grant No. 03ET7071U.

Conflict of interest The authors declare that they have no conflicts of interest.

Availability of data and material Available upon request to the authors.

Open Access This article is licensed under a Creative Commons Attribution 4.0 International License, which permits use, sharing, adaptation, distribution and reproduction in any medium or format, as long as you give appropriate credit to the original author(s) and the source, provide a link to the Creative Commons licence, and indicate if changes were made. The images or other third party material in this article are included in the article's Creative Commons licence, unless indicated otherwise in a credit line to the material. If material is not included in the article's Creative Commons licence and your intended use is not permitted by statutory regulation or exceeds the permitted use, you will need to obtain permission directly from the copyright holder. To view a copy of this licence, visit http://creativecommons.org/licenses/by/4.0/.

\section{References}

Alemela PR, Fanaca D, Hirsch C, Sattelmayer T, Schuermans B (2010) Determination and scaling of thermoacoustic characteristics of premixed flames. Int J Spray Combust Dyn 2:169-198

Ashgriz N (2011) Handbook of atomization and sprays: theory and applications. Springer, New York

Bade S, Wagner M, Hirsch C, Sattelmayer T, Schuermans B (2013) Design for thermo-acoustic stability: modeling of burner and flame dynamics. J Eng Gas Turbine Power 135:111502-1-7

Bobusch BC, Cosic B, Moeck JP, Paschereit CO (2013) Optical measurement of local and global transfer functions for equivalence ratio fluctuations in a turbulent swirl flame. In: Proceedings of the ASME turbo expo: GT2013-95649

Candel S, Durox D, Schuller T, Bourgouin JF, Moeck JP (2013) Dynamics of swirling flames. Annu Rev Fluid Mech 46:147-173

Clark TP (1958) Studies of $\mathrm{OH}, \mathrm{CO}, \mathrm{CH}$, and $\mathrm{C} 2$ radiation from laminar and turbulent propane-air and ethylene-air flames. Technical note 4266, National Advisory Committee for Aeronautics, Washington

Docquier N, Lacas F, Candel S (2002) Closed-loop equivalence ratio control of premixed combustors using spectrally resolved chemiluminescence measurements. Proc Combust Inst 29:139-145 
Ducruix S, Candel S, Durox D, Schuller T (2003) Combustion dynamics and instabilities: elementary coupling and driving mechanisms. J Propuls Power 19:722-734

Eckstein J (2004) On the mechanisms of combustion driven lowfrequency oscillations in aero-engines. Dissertation, Technical University of Munich

Eckstein J, Freitag E, Hirsch C, Sattelmayer T, von der Bank R, Schilling T (2005) Forced low-frequency spray characteristics of a generic airblast swirl diffusion burner. J Eng Gas Turbine Power 127:301-306

Freitag E (2009) On the measurement and modelling of flame transfer functions at elevated pressure. Dissertation, Technical University of Munich

Guyot D, Guethe F, Schuermans B, Lacarelle A, Paschereit CO (2010) $\mathrm{CH}^{*} / \mathrm{OH}^{*}$ chemiluminescence response of an atmospheric premixed flame under varying operating conditions. In: Proceedings of the ASME Turbo Expo:GT2010-23135

Hardalupas Y, Orain M (2004) Local measurements of the timedependent heat release rate and equivalence ratio using chemiluminescent emission from a flame. Combust Flame 139:188-207

Huang Y, Yang V (2009) Dynamics and stability of lean-premixed swirl-stabilized combustion. Prog Energy Combust Sci 35:293-364

Józsa V, Kun-Balog A (2015) Spectroscopic analysis of crude rapeseed oil flame. Fuel Process Technol 139:61-66

Keller JJ (1995) Thermoacoustic oscillations in combustion chambers of gas tuirbines. AIAA J 33:2280-2287

Kojima J, Ikeda Y, Nakajima T (2000) Spatially resolved measurement of $\mathrm{OH}^{*}, \mathrm{CH}^{*}$, and $\mathrm{C}_{2} *$ chemiluminescence in the reaction zone of laminar methane/air premixed flames. Proc Combust Inst 28:1757-1764

Konrad W, Brehm N, Kameier F, Freeman C, Day IJ (1998) Combustion instability investigations on the br710 jet engine. J Eng Gas Turbine Power 120:34-40

Lauer MRW (2011) Determination of the heat release distribution inturbulent flames by chemiluminescence imaging. Dissertation, Technical University of Munich

Lee H, Seo S (2015) Experimental study on spectral characteristics of kerosene swirl combustion. Procedia Eng 99:304-312

Lieuwen TC (2013) Unsteady combustor physics. Cambridge University Press, Cambridge

Lieuwen TC, Yang V (2005) Combustion instabilities in gasturbine engines: operational experience, fundamental mechanisms, and modeling. American Institute of Aeronautics and Astronautics Inc, Reston

Lieuwen TC, Zinn BT (1998) The role of equivalence ratio oscillationsin driving combustion instabilities in low nox gas turbines. Symp Combust Proc 27:1809-1816

Lieuwen TC, Torres H, Johnson C, Zinn BT (2001) A mechanism of combustion instability in lean premixed gas turbine combustors. J Eng Gas Turbine Power 123:182-189

Muruganandam T, Kim BH, Morrell M, Nori V, Patel M, Romig B, Seitzman J (2005) Optical equivalence ratio sensors for gas turbine combustors. Proc Combust Inst 30:1601-1609
Najm HN, Paul PH, Mueller CJ, Wyckoff PS (1998) On the adequacy of certain experimental observables as measurements of flame burning rate. Combust Flame 113:312-332

Nori VN (2008) Modeling and analysis of chemiluminescence sensing for syngas, methane and jet-a combustion. Dissertation, Georgia Institute of Technology

Orain M, Hardalupas Y (2010) Effect of fuel type on equivalence ratio measurements using chemiluminescence in premixed flames. C R Mécanique 338:241-254

Orain M, Hardalupas Y (2011) Measurements of local mixture fraction of reacting mixture in swirl-stabilised natural gas-fuelled burners. Appl Phys B 105:435-449

Panoutsos C, Hardalupas Y, Taylor A (2009) Numerical evaluation of equivalence ratio measurement using $\mathrm{OH}^{*}$ and $\mathrm{CH}^{*}$ chemiluminescence in premixed and non-premixed methane-air flames. Combust Flame 156:273-291

Paschereit CO, Schuermans B, Polifke W, Mattson O (2002) Measurement of transfer matrices and source terms of premixed flames. J Eng Gas Turbine Power 124:239-247

Pretzler G, Jäger H, Neger T, Philipp H, Woisetschläger J (1992) Comparison of different methods of abel inversion using computer simulated and experimental side-on data. Z Naturforsch A: Phys Sci 47:955-970

Reader J, Sansonetti CJ, Bridges JM (1996) Irradiances of spectral lines in mercury pencil lamps. Appl Opt 35:78-83

Reyes J, Kailasanathan A, Ahmed K (2018) Relationship between the chemiluminescence intensity ratio of $\mathrm{C}_{2} *$ and $\mathrm{CH}^{*}$, charge pressure, and equivalence ratio for gasoline. Energy Fuels 32:10933-10940

Sangl J, Mayer C, Sattelmayer T (2011) Dynamic adaptation of aerodynamic flame stabilization of a premix swirl burner to fuel reactivity using fuel momentum. J Eng Gas Turbine Power 133:071501-1-11

Sattelmayer T (2003) Influence of the combustor aero dynamics on combustion instabilities from equivalence ratio fluctuations. J Eng Gas Turbine Power 125:11-19

Stadlmair NV (2018) Influence of water injection on thethermoacoustic stability of a lean-premixed combustor. Dissertation, Technical University of Munich

Yi T, Santavicca DA (2009) Flame spectra of a turbulent liquid-fueled swirl-stabilizedlean-direct injection combustor. J Propuls Power 25:1058-1067

Zhu M, Dowling AP, Bray KNC (2001) Self-excited oscillations in combustors with spray atomizers. J Eng Gas Turbine Power 123:779-786

Publisher's Note Springer Nature remains neutral with regard to jurisdictional claims in published maps and institutional affiliations. 